\title{
Specificity of antinuclear antibodies in primary biliary cirrhosis
}

Department of Internal Medicine, Chung Shan Medical and Dental College, Taichung, Taiwan T-Y Chen

G J Tsay

Department of Anatomy M-J Chou

School of Medical Technology S-L Lee Correspondence to: Dr Tsay,

Department of Medicine, Chung Shan Medical and Dental College, 23 Section 1, Taichung Kang Road, Taichung, Taiwan.

Accepted for publication 2 September 1994

Ming-Jen Chou, Shu-Ling Lee, Tzy-Yen Chen, Gregory J Tsay

Abstract

Objective-To study the specific autoantibodies against nuclear antigens in patients with primary biliary cirrhosis (PBC).

Methods-Sera from 21 patients with PBC were tested for antinuclear antibody (ANA) by indirect immunofluorescence on human epithelial (HEp)-2 cells, and for antibodies to various nuclear antigens by enzyme linked immunosorbent assay (ELISA) using different purified proteins or recombinant proteins as antigens.

Results-ANA detected in 10 of 21 patients (48\%) with PBC included five anticentromere antibody (ACA), two speckled, two homogeneous and one nuclear dot staining. ACA were present in $24 \%$ of PBC patients. By ELISA, antihistone antibodies were detected in $81 \%$ of PBC patients, anti-ssDNA antibodies in $71 \%$ and anti-dsDNA in $10 \%$, antitopoisomerase-1 antibodies in $24 \%$, anti$\mathrm{Sm} / \mathrm{RNP}$ antibodies in $24 \%$, anti-La48(SS-A) antibodies in $21 \%$, and anti-Ro-60(SS-A) and anti-Ro-52(SS-A) antibodies in $30 \%$ and $25 \%$, respectively. Conclusions-The high frequencies of various antibodies directed against intracellular proteins and nucleic acids in patients with PBC suggests that PBC is a multisystem autoimmune disease which is similar to other systemic autoimmune diseases.

(Ann Rheum Dis 1995; 54: 148-151)

Primary biliary cirrhosis (PBC) is a chronic idiopathic liver disease characterised by the destruction of intrahepatic bile ducts, portal inflammation and scarring, and eventually leading to liver failure. The aetiology of PBC is unknown, but evidence supports an autoimmune process. ${ }^{1} \mathrm{~A}$ common feature of autoimmune diseases is a humoral immune response manifested by the presence of autoantibodies targeted against intracellular proteins and nucleic acids. ${ }^{2}$ Antimitochondrial antibodies (AMA) are a hallmark of PBC and are detected in up to $95 \%$ of patients with PBC. ${ }^{134}$ In contrast, antinuclear antibodies (ANA) in patients with PBC are less common. Anticentromere antibodies (ACA) and other nuclear antibodies have been reported in patients with PBC. ${ }^{5-8}$ With the introduction of new autoantigens which can be purified from tissues or from recombinant proteins, a greater number of specific autoantibodies have been detected by a more sensitive immunoenzymatic assay. ${ }^{2}$ It was the aim of this study to determine the specificity and frequency of ANA in the sera of patients with PBC as detected by immunofluorescence and by enzyme linked immunosorbent assay (ELISA) using different purified proteins or recombinant proteins as antigens.

\section{Patients and methods}

SERA

Sera were collected from 21 patients with PBC and 20 healthy controls. During the study, the number of patients with PBC was increased to a total of 24 ; results for the additional three patients are included where available. The diagnosis of PBC was based on the presence of all of the following: (a) evidence of continuous liver disease based on a history of biochemical abnormalities for more than three months; (b) serum alkaline phosphatase concentrations greater than three times normal; (c) positivity for AMA; (d) a diagnostic or compatible liver histology. ${ }^{9}$ The control group of age and sex matched healthy, asymptomatic individuals was drawn from hospital staff. All sera were collected at Chung Shang Medical and Dental College Hospital and National Taiwan University Hospital, Taiwan.

IMMUNOFLUORESENCE TEST FOR AMA AND ANA Sera were tested for AMA by indirect immunofluorescence of frozen sections of mouse kidney and stomach. ANA were detected using human epithelial (HEp)-2 cells (Antibodies Inc. CA, USA) as described previously. ${ }^{10}$ AMA and ANA were considered positive at a 1/20 dilution and 1/80 dilution, respectively.

IMMUNODIFFUSION

Immunodiffusion was performed using extractable nuclear antigen of rabbit thymus (lyophilised extract from Pel-Freeze Biologicals, Rogers, AR, USA) and human spleen according to the methods of Tan. ${ }^{10}$

ELISA

ELISA was performed according to the method of Rubin et al. ${ }^{11}$ All sera were assayed at a dilution of $1 / 200$. Briefly, Microwell plates were coated overnight at room temperature with $100 \mu \mathrm{l} /$ well of $5 \mu \mathrm{g} / \mathrm{ml}$ antigens in 50 $\mathrm{mmol} / 1 \quad \mathrm{Na}_{2} \mathrm{CO}_{3} / \mathrm{NaHCO}_{3}$ buffer, $\mathrm{pH} \quad 7 \cdot 2$. Wells were blocked with gelatin, washed with 
phosphate buffered saline (PBS)-Tween and sequentially incubated with human sera (1:200 dilution) and peroxidase conjugated goat antihuman immunoglobulin. Substrate solution containing 2,2' azino-di-(3-ethylbenzthiazolin-6-sulphonic acid) $1 \mathrm{mg} / \mathrm{ml}$ and $0.005 \%$ hydrogen peroxide in $0.1 \mathrm{~mol} / \mathrm{l}$ Mcilvaine's buffer was used for the peroxidase reaction.

\section{ANTIGENS}

Native DNA (Calbiochem, La Jolla, CA, USA) was bound to microtitre plates precoated with methylated bovine serum albumin and digested with $S 1$ nuclease to remove any denatured regions. Denatured DNA was prepared by boiling and quick cooling and was absorbed to plate at $2.5 \mu \mathrm{g} / \mathrm{ml}$.

Total histones were also obtained from Calbiochem. ${ }^{11}$ Purity was greater than $95 \%$ as judged by sodium dodecyl sulphatepolyacrylamide gel electrophoresis. Histones were diluted to $2.5 \mu \mathrm{g} / \mathrm{ml}$ in PBS for adsorption to plates.

$\mathrm{Sm}$ and $\mathrm{Sm} / \mathrm{RNP}$ antigens were purified from rabbit thymus powder (Pel-Freeze) sera characterised as anti-Sm only, anti-Sm/RNP, and anti-RNP only, were identified as reported previously. ${ }^{12}$

Recombinant proteins of $\operatorname{Ro}(\mathrm{SS}-\mathrm{A})$ and $\mathrm{La}(\mathrm{SS}-\mathrm{B})$ for use in the ELISA were kindly provided by Dr Edward K L Chan and Eng M Tan, W M Keck Autoimmune Disease Center,
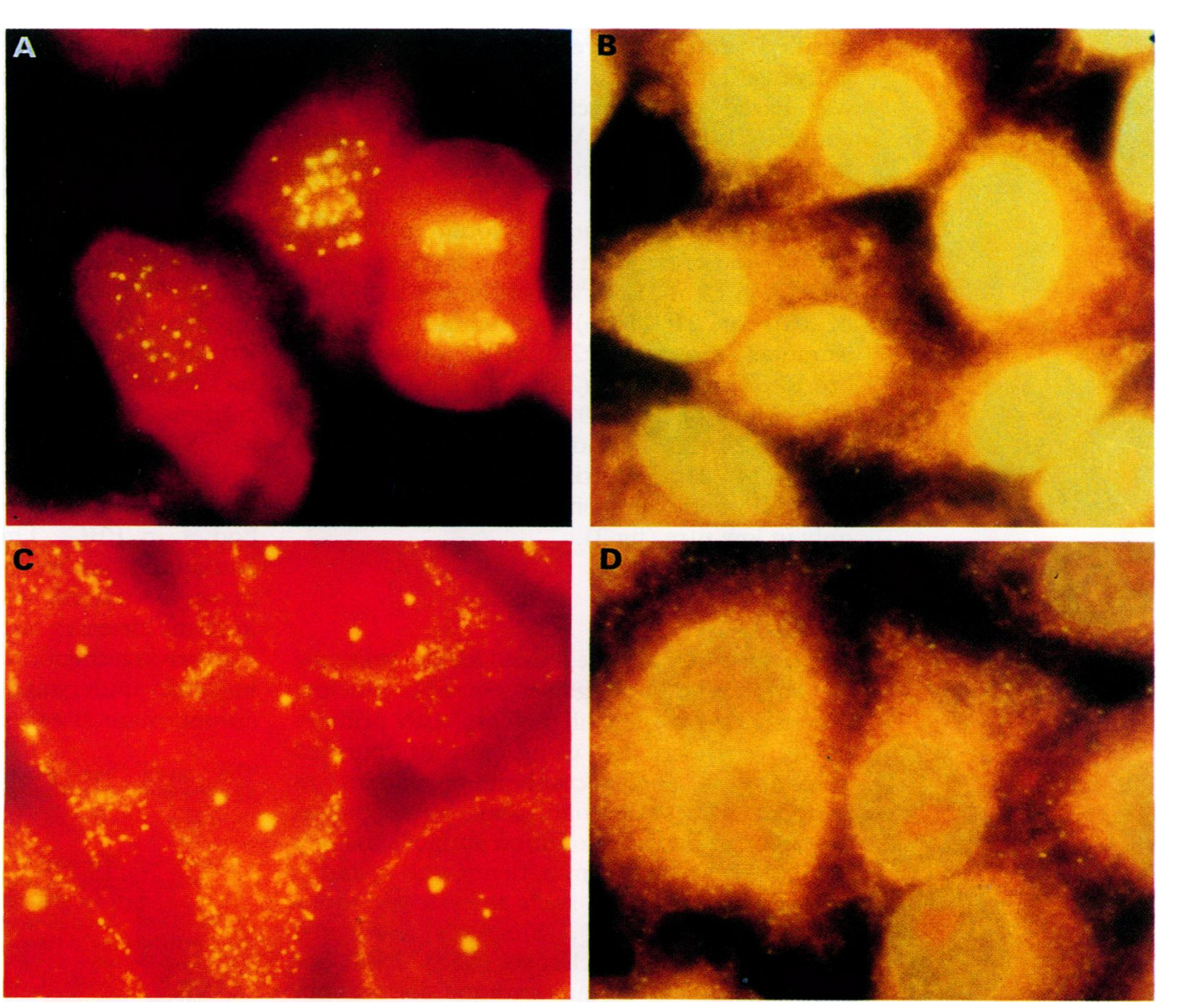

The Scripps Research Institute, La Jolla, CA, USA. The recombinant proteins rRo-52(SSA) (at a dilution of $1: 16000$ ) and rRo-60(SSA) (1:1000 dilution) were for the $52 \mathrm{kDa}$ and $60 \mathrm{kDa} \mathrm{Ro}$ (SS-A) antigens, respectively. The recombinant protein $\mathrm{rLa}-48$ (SS-B) was for the $48 \mathrm{kDa} \mathrm{La}(\mathrm{SS}-\mathrm{B})$ antigen and was used at $1: 8000$ dilution.

IMMUNOFLUORESCENCE

When HEp-2 cells were used as substrate, 10 of 21 sera $(48 \%)$ from patients with PBC produced positive nuclear fluoresence. Of these 10 ANA positive sera, five had ACA (fig 1A), two had homogenous patterns (fig 1B), one showed nuclear dots (fig 1C), and two had speckled patterns (fig 1D). The ACA were characterised by a discrete speckled pattern on resting tissue culture cells and by a distinct pattern on chromosomes of dividing cells. The nuclear dot pattern was a distinct one of two to seven discrete nuclear dots which varied in size and number among individual cells and differed from centromere staining in that they were larger, fewer in number, and not seen in mitotic cells or on metaphase chromosome spreads. Mitochondrial staining of the cytoplasm is evident in figure $1 \mathrm{~B}, \mathrm{C}$ and $\mathrm{D}$.

\section{IMMUNODIFFUSION}

Using extracts of rabbit thymus and human spleen as sources of antigen, antibodies to Ro

Figure 1 Patterns of nuclear immunofluorescence on human epithelial-2 cells observed in the patients with primary biliary cirrhosis. A: Anticentromere staining; B: homogenous staining; C: nuclear dot staining; D: fine speckled staining. Typical staining of chromosome in mitotic cells in $A$; mitochondrial staining of cytoplasm is seen in $B, C$, and $D$. 


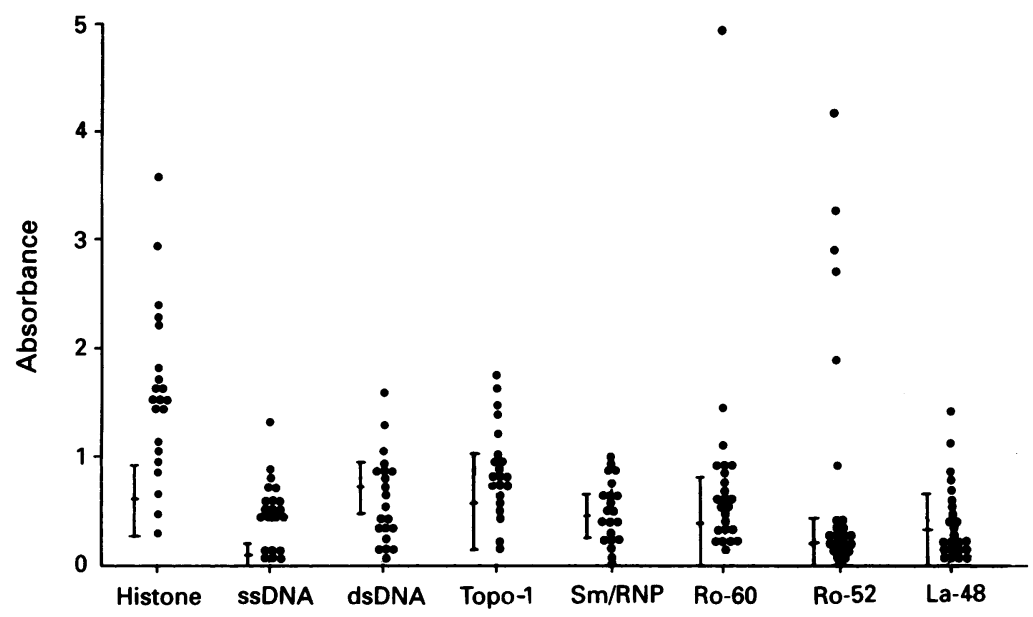

Figure 2 Antibodies to histones, single stranded DNA (ssDNA), double stranded DNA (dsDNA), and topoisomerase-1 (Topo-1) detected by ELISA using purified antigens as substrates and antibodies to the recombinant proteins of the $60 \mathrm{kDa}$ form of $\operatorname{Ro}(S S-A)$, the $52 \mathrm{kDa}$ form of $R o(S S-A)$ and the $48 \mathrm{kDa}$ form of $L a(S S-B)$ in patients with PBC.

were found in two of $21(10 \%)$ and antibodies to $\mathrm{La}$ in one of $21(5 \%)$ patients with $\mathrm{PBC}$ by means of immunological identity with reference sera. One was found to be immunologically distinct from a series of antibodies reacting with other known cellular antigens including Sm, nRNP, Ro, La, topoisomerase-1, Jo-1, proliferating cell nuclear antigen, and PM-Scl.

ELISA

Figure 2 shows the results of using different purified proteins or recombinant proteins as antigens. The normal value of the absorbance was based on the results from 20 normal control subjects. Values greater than mean $+2 S D$ were considered to indicate increased antibodies.

Antibodies to histone were found in 17 of 21 (81\%) patients with PBC, antibodies to ssDNA in 15 of $21(71 \%)$, antibodies to nDNA in two of $21(10 \%)$, antibodies to topoisomerase- 1 in five of $21(24 \%)$, antibodies to $\mathrm{Sm} / \mathrm{RNP}$ in five of $21(24 \%)$, antibodies to Ro60 in seven of $24(30 \%)$, antibodies to Ro-52 in six of $24(25 \%)$, and antibodies to La-48 in five of $24(21 \%)$. Antibodies to native DNA, $\mathrm{Sm} / \mathrm{RNP}$, and topoisomerase-1 were detected only in low titre (fig 2).

\section{Discussion}

In the present study we looked for the presence of autoantibodies against specific nuclear antigens in the sera of patients with primary biliary cirrhosis by using various purified autoantigens and recombinant proteins as antigens. These autoantigens were chosen because they include common antigens that are recognised by sera from patients with systemic autoimmune diseases such as systemic lupus erythematosus (SLE), Sjögren's syndrome (SS), and systemic sclerosis (SSc). PBC has been regarded as an autoimmune disease, but there remains some controversy as to whether it is an organ specific or a multisystem autoimmune disease. In this study antihistone antibody was found in $81 \%$ of PBC patients, anti-ssDNA in $71 \%$, anti-La-48(SS-B) in $21 \%$, anti-Ro-60(SS-A) in $30 \%$, anti-Ro52 (SS-A) in $25 \%$ and anti-Sm/RNP in $24 \%$. This heterogeneity of ANA in our patients with PBC suggests a heterogeneous immunological background comparable to that in patients with systemic autoimmune disease, and that PBC may be regarded as multisystem autoimmune disease.

The frequency of ANA on HEp-2 cells by immunofluoresence in the present study (48\%) was comparable to others reported previously. ${ }^{78}$ The patterns of ANA were diverse and included ACA, speckled, homogenous, and nuclear dot staining. Bernstein et $a l^{7}$ and Cassani et $a l^{8}$ reported frequencies of nuclear dot staining in PBC as $13 \%$ and $17 \%$, respectively, and suggested that this pattern might be a serological marker for PBC. We found nuclear dot staining in one of 21 sera from patients with $\mathrm{PBC}$; an increased incidence of ACA was also found. These two antibodies seem to be unique in patients with PBC.

Antihistone antibodies are generally considered to be related to drug induced lupus. An association between antihistone antibodies and clinical features has also been reported. ${ }^{213} 14$ They were found in $81 \%$ of sera from patients with PBC in our study-a frequency comparable to that found in drug induced lupus, ${ }^{2}$ in generalised morphea, ${ }^{13}$ and in juvenile chronic arthritis with uveitis. ${ }^{14}$ Such a high prevalence of antihistone antibodies in PBC has not been reported previously and its significance in PBC needs further study.

It has been noted that PBC is often associated with Sjögren's syndrome. ${ }^{15}$ This study shows that the frequency of anti-Ro52(SS-A), anti-Ro-60(SS-A), and anti-La48(SS-B) antibodies in the sera of patients with PBC was $20-30 \%$. This frequency of these autoantibodies in PBC was higher than that reported in a previous study, ${ }^{7}$ and as antiRo(SS-A) and anti-La(SS-A) are antibodies specific for Sjögren's syndrome, it provides confirmation that PBC may often associate with Sjögren's syndrome.

Using a sensitive immunoenzymatic assay, we found a distinct profile of antinuclear antibodies in PBC. The varying frequencies of autoantibodies we observed were similar to those associated with other systemic autoimmune diseases such as SLE, SS, and SSc. Further investigation of these associations may improve understanding of PBC and other autoimmune diseases.

This study was partly supported by grant NSC 82-0409-B-040-016 from National Science Council, Taiwan.

1 James S P, Hoofnagle J H, Strober W, Jones E A. Primary biliary cirrhosis: a model autoimmune disease. Ann Intern Med 1983; 99: 500-12.

2 Tan E M. Antinuclear antibodies: diagnostic markers for autoimmune diseases and probes for cell biology. $A d v$ Immunol 1989; 44: 93-151.

3 Berg P A, Klein R, Lindenborn-Fotinos J, Kloppel W. ATPase-associated antigen (M2): marker antigen for serological diagnosis of primary biliary cirrhosis. Lancet 1982; ii: 1423-6.

4 Chou M-J, Lai M-Y, Lee S-L, Tsay G J. Reactivity of antimitochondrial antibodies in primary biliary cirrhosis 
and systemic sclerosis. $\mathcal{f}$ Formosan Med Assoc 1992; 91: 1075-80.

5 Bernstein B M, Callender M E, Neuberger J M, Hughes G $R$ V, Williams $R$. Anticentromere antibody in primary biliary cirrhosis. Ann Rheum Dis 1982; 41: 612-4

6 Kurki P, Gripenberg M, Teppo A-M, Salaspuro M. Profiles of antinuclear antibodies in chronic active hepatitis, primary biliary cirrhosis and alcoholic liver disease. Liver 1984; 4: 134-8.

7 Bernstein R M, Neuberger J M, Bunn C C, Caallender G $R$, Hughes V, Williams R. Diversity of autoantibodies in primary biliary cirrhosis and chronic active hepatitis. Clin Exp Immunol 1984; 55: 553-60.

8 Cassani F, Bianchi F B, Lenzi M, Volta U, Pisi E. Immunomorphological characterisation of antinuclear antibodies in chronic liver disease. $\mathcal{F}$ Clin Pathol 1985; 38: 801-5.

9 Williamson J S, Chalmers D M, Clayden A D, Dixon M F, Ruddell W S, Losowsky M S. Primary biliary cirrhosis and chronic active hepatitis: an examination of clinical biochemical, and histopathological features in differential diagnosis. f Clin Pathol 1985; 38: 1007-12.
10 Tan E M. Relationship of nuclear staining patterns with precipitating antibodies in systemic lupus erythematosus. f Lab Clin Med 1967; 70: 800-2.

11 Rubin R L, Joslin F G, Tan E M. An improved ELISA for anti-native DNA by elimination of interference by antihistone antibodies. F Immunol Methods 1983; 63: 359-66.

12 Tsay G J, Chan E K L, Peebles C L, Pollard K M, Tan E $M$. An immunoassay differentiating sera with antibodies to $\mathrm{Sm}$ alone, antibodies to $\mathrm{Sm} / \mathrm{RNP}$ complex, and antibodies to RNP alone. Arthritis Rheum 1987; 30: antibodies

13 Sato S, Ihn H, Soma $Y$, et al. Antihistone antibodies in patients with localized scleroderma. Arthritis Rheum 1993; 36: $1137-41$

14 Ostensen M, Fredriken K, Kass E, Rekvig O P. Identification of antihistone antibodies in subset of juvenile chronic arthritis. Ann Rheum Dis 1989; 48: 114-7.

15 Alarcon-Segovia D, Diaz-Jouanen E, Fishbein E. Features of Sjögren's syndrome in primary biliary cirrhosis. Ann Intern Med 1973; 79: 31-6. 